\title{
Study on APP for the Construction of Campus Art Culture based on Mobile Client
}

\author{
Zi Wang ${ }^{1, a}$ \\ ${ }^{1}$ College of Fine Arts, Beihua University, 132013, Jilin City, China \\ azi_wang001@126.com
}

Keywords: APP; Campus art culture; Mobile client.

\begin{abstract}
. with the rapid development of network technology and the need widely of campus art culture propaganda, the APP combination of Internet and mobile client is the expression of following the trend of the times. The mobile client was used to transmission media is an innovation; a new level and a new develop method to introduce the campus art culture. In this paper, the telephone APP was proposed in order to propagate the cam-pus art environment and facilities functions for freshmen and visitors.
\end{abstract}

\section{Introduction}

Campus landscape is essentially the accumulation of history, diverse style shaping has meaning and value of their education, planning and design of campus landscape should respect the past and welcome in-innovation, which is regarded as a new page style treasury. Basically, the campus design is a citizen of art belonging to our cultural significance and of great value to resonate. Greeks have their assembly room, the Romans had their forum, the medieval cathedral and town square, Renaissance palaces and privileged people have territory in the 19th century who have business centers, public transport and government, the campus is only for us in this generation of public venues and sites marked contribution to the process.

Multimedia operating systems include real-time scheduling, multimedia, data conversion and synchronization control, drive and control multimedia devices and a user interface with graphical and audiovisual capabilities and so on. Multimedia authoring tools to create multimedia applications software tools collectively, it can be text, graphics, images, animation, video and audio and other multimedia in-formation control and management, and they are required to connect into complete multimedia applications. Multimedia application developer using a computer language or multimedia authoring tools to create multimedia applications software products, is a direct user-oriented. The multi-use multimedia applications is computer multimedia technology application in the teaching of art and traditional art teaching, compared with what the advantages and practical sense?

\section{The modern school building}

Where the planning and design of cultural and artistic significance of University environment as the most important institutions of higher learning is an important creator and disseminator of cities and regions of civilization, she is both a city and regional economic boosters, but also a propagator of cities and regions of advanced culture, to improve the city's economic and urban image plays a pivotal role. With the development of society, the world entered the era of knowledge economy, science and technology as the primary productive force is referred to an unprecedented height, universities not only bear the teaching, the basic task of scientific research, have become knowledge into an important part of the productive forces. Some cities and regions proposed the development of "teacher economy", "academician economy", "University of Economics" slogan, the use of colleges and universities personnel, scientific and technological achievements advantage of the economic entity established to build a pillar industry and promote the development of related industries, universities become cities and regions a new economic growth point. In addition, with the introduction of city management theory, the concept of higher education institutions and a fundamental change in the 
way school, university logistics service this public resource to society, to enter the market. Manage their business. The reforms focused on the state's financial investment in teaching resources, to expand enrollment and create the conditions for improving the teaching environment.

In the past, our school building, after the Ming and Qing, the Republic of China and various times after the war and so on, the change is very fast rise and fall. Representing a unique style of college, most already decadent, and some have even been removed; since the reform and opening up of China's increasing investment in education, popularization of the nine-year compulsory education, the college entrance examination enrollment, improve life education. Early in the courtyard of the campus environment has failed to meet the needs of today's schools, instead of open campus landscape, so as to make the campus landscape planning new ideas, new ideas. However, due to the pace of development in recent years, the school is very fast, especially in the many universities today in order to expand enrollment, the founder of the new high-level comprehensive university have new university city, since in the past, the school began to build the economy and standardization of school.

\section{Multimedia assisted teaching}

In the current art theory teaching in primary and secondary schools, the use of computer-assisted instruction has two aspects, one multimedia assisted teaching, which is the use of multimedia courseware assisted teaching; the second is the use of computer software to art theory teaching, which is the work of a variety of internet multimedia software to assist teaching.

The term "internet multimedia" is from the art theory instrument digital interface (Art theory Instrument Digital Interface) abbreviation. It is an application of computer multimedia technology in the audio field. Entire internet multimedia system is including synthesizers, computer art theory software, audio, computers, internet multimedia connections, mixers, digital recorders and other peripheral devices. The computer can be derived from a keyboard instrument or other internet multimedia instruments produce sound information into digital information into the computer.

"Art theory curriculum standards," pointed out: "By providing an open and entertaining art theory learning scenarios to stimulate students' curiosity and desire to explore art theory, and guide students to impromptu free play as the main features of inquiry and creativity, attention to development students explore the process of creative thinking. "The internet multimedia technology into art theory teaching can greatly improve classroom teaching interesting; create art theory learning scenarios to stimulate students' curiosity about the world of art theory and the desire to explore, to guide students to use the computer network resources and internet multimedia technology impromptu free play of inquiry and creativity. In teaching, each student can share the authoring software, make full use of the resources provided by the instructor, who have learned to use art theory knowledge, give full play to their imagination and creativity, creation of art theory works. The conventional art theory teaching mostly on paper, has been repeated on the radio theoretical knowledge, this is obviously a great impact on teaching effectiveness, to a large extent influence the development of students' creative ability. But after using internet multimedia technology and multimedia technology, the effect of using these two techniques compatible assisted instruction on much better than traditional teaching effect, internet multimedia file in teaching-related applications, and through audio, synthesizer, audio peripherals, etc.

\section{Internet multimedia application in teaching}

First, the traditional teaching of singing lessons, teachers rely mainly on piano accompaniment and supporting materials to the accompaniment of song accompaniment recordings for students, which would likely generate the following situations:

Use the piano for the students to learn to sing the song accompaniment, speed is not easy to grasp was so accurate, are often sing again a kind of situation, even a sense of rhythm, the sense of speed is also very good teacher is very difficult to accurately labeled in accordance with the speed of the song They were playing. Art theory teacher of piano playing level everyone is not the same, some high 
piano teacher skills, can follow the original teaching reference spectrum accompaniment to play on, but once Professor songs are not original spectrum accompaniment, or students when you need to transpose learning to play concerts process, with a teacher's performance there will be two editions of bias, and some may even be "a big difference", not to mention those with poor skills piano teacher. Use accompaniment for students, it is hard to accurately control the recording time to start playing and stop time, once the student error or pause in the singing process, teachers will find just pause again Juana place continued to sing the song,

When using the traditional accompaniment for the students singing accompaniment, song tone number is extremely difficult to change, even if some of the recorder or player with ascending, descending tone function, often accompanied by the recording speed changes occur at the same time, not faster is slower, so that teachers who really headache ah. Some teachers proficient Piano Improvisation in classroom activities, regardless of what kind of change the song key signatures can come in handy, blossoms so, but the mood of the song performance will not help give students often command a bit to more good to mobilize students' emotion, this time we will see a hand piano teacher, one hand waving in the air, the students inside the ear to hear only the left-hand bass piano accompaniment, to think of it is "unique flavor." The above circumstances I believe that teachers in the teaching activities have ever met, but also in the traditional teaching activities can not be avoided, but now it is different, we will internet multimedia device is introduced into the teaching activities, these problems would be solved.

\section{The role of technology in modern internet multimedia art theory teaching}

In the teaching of art theory, the art theory of this preparation should be and teaching other subjects are not the same, but the current situation is still the case, still, like other subjects, like a textbook, a lesson plan, a box of chalk, a piano. Only occasionally, when teachers will use computer-assisted instruction to enrich teaching art theory, but even computer-assisted instruction or teacher notes are written on the blackboard in a variety of characters, or put something on the books originally projected onto the blackboard so traditional Teaching is not much difference. Workers are use internet multimedia Engineering Technology lesson is what Nick? Teachers can repeatedly song, audition song, song accompaniment, listening links art theory, choral song links, notes, etc. all use to learn art theory sound, made into a file format internet multimedia workers, and these files in class when casually displayed based on the needs of teaching can be done "as long as you need, he can do it 'evening this effect, such as, art thermal ensemble, you can easily put a certain part of the sound, whether it is the tone of this file, speed, range, and so on classroom presentation and use. internet multimedia work out innovative internet multimedia technology has greatly improved from art theory the effect of teaching; this is updating the art theory teaching in the true sense.

Teaching art theory courses of professional composer as a teaching tool and is affected by the restrictions, the students and with the creation of art theory works when you want to achieve the effect of ordinary orchestra is very difficult. Therefore, in the conventional art theory teaching mostly on paper, has been repeated on the radio theoretical knowledge, this is obviously a great impact on teaching effectiveness, to a large extent influence the development of students' creative ability. But after using internet multimedia technology and multimedia technology, the effect of using these two techniques compatible assisted instruction on much better than traditional teaching effect, internet multimedia file in teaching-related applications, and through audio, synthesizer, audio peripherals, etc. equipment convey high-quality audio information, so that students in the process of playing the feeling is very real, and the use of internet multimedia technology side of the sheet art theory while listening to the effect of modification, it is easy to develop students' creativity.

Faced with an emergency during the class is a normal phenomenon, no matter what class will encounter in the classroom incident, which requires mastery of wit teachers teaching higher. In art theory teaching, such as learning to sing songs, in one place encountered rhythm or other reasons, when there is no solution, then you can use internet multimedia technology shift function, the playback speed to slow down, let students repeated simulation and audition. For example, a student in 
learning songs, original songs set the tone for students to sing it very difficult, but they did not do demotion teacher preparation, this time we can use internet multimedia technology demotion feature to pitch songs automatically reduces, but before doing these teachers will only need to be stored in memory in internet multimedia file internet multimedia file certain good, to prepare for contingencies.

\section{Summary}

To sum up, we can see modern technology and modern teaching media play an important and irreplaceable for internet multimedia technology in modern art theory education professional teaching, not only has a better use of technology in art theory course, still audition drill has a better ability to use the application in art theory appreciation teaching is a strong feature. Through real practical teaching can know internet multimedia technology in modern art theory teaching has a very large potential applications of computer technology and will continue to update and develop in the future, this technology will certainly make art theory teaching occurs relatively large Variety.

\section{References}

[1] Kekang information technology and curriculum deep integration theory and method. art research. 2005 (0internet multimedia)

[2] Jiaoyao Guang basic education curriculum reform in the information technology and curriculum integration: problems and countermeasures. art Research 2004 (internet multimedia2).

[3] Wang Li. Application of Multimedia carry art theory teaching to improve teaching effectiveness . Primary and Secondary audio-visual. 2004 (internet multimedia2)

[4] Song Jin. In the aesthetic core of art theory education reform . Central Conservatory of Art theory. 2004 (04)

[5] Yao Xiaohui, Wang recorded. Rational Thinking of Information Technology and Curriculum Integration . Primary and Secondary audio-visual. 2004 (internet multimediainternet multimedia)

[6] Chen Weidong, Limang teachers of information technology and curriculum integration training design . Vocational and Technical Education. 2004 (07) [7] Wucai Juan Modern Art Technology in Art theory Teaching . Primary and Secondary audio-visual. 2004 ( Ointernet multimedia)

[7] Sun Taifeng Application information technology in art theory education. Changchun Normal University. 2003 (02)

[8] Zhang mirror. Multimedia applications in art theory education . Henan Vocational and Technical Teachers College. 2003 (0internet multimedia)

[9] Xia Lisheng Comparison and thinking of digital multimedia art theory education and traditional art theory education . China Art Technology. 2002 (internet multimediainternet multimedia)

[10] Sun silver of Computer Art theory Teaching System in College Art theory Teaching Grand Week, 20internet multimediainternet multimedia, 3 (internet multimedia8): internet multimedia2-internet multimedia3

[11]Zhang Hong digitized art theory teaching resources used in elementary art theory teaching Chinese art theory education, 20internet multimedia0, 6 (5): 2-3

[12]Zhou Ya dragonfly modern ear training teaching philosophy research [D]. Liaoning Normal University, 20internet multimedia. 